\title{
FORMULATION AND IN VITRO EVALUATION OF RAMELTEON TABLETS FOR COLON DRUG DELIVERY SYSTEM BY COMPRESSION COATING
}

\author{
TRINADHA RAO M., PARIMALA Y., YAMINI M., PHANINDRA CVS, SRINIVASA RAO Y.
}

Department of Pharmaceutics, Vignan Institute of Pharmaceutical Technology, Duvvada, Visakhapatnam 530049, India *Email: thrinadh_81@rediffmail.com

Received: 28 Nov 2020, Revised and Accepted: 30 Jan 2021

\section{ABSTRACT}

Objective: Ramelteon, is a sleep agent that selectively binds to the $\mathrm{MT}_{1}$ and $\mathrm{MT}_{2}$ receptors in the suprachiasmatic nucleus (SCN), instead of binding to $\mathrm{GABA}_{\mathrm{A}}$ receptors. In the present research work, the formulation of ramelteon targeted to colon by using various polymers developed.

Methods: Colon-targeted tablets were prepared in two steps. Initially, core tablets were prepared and then the tablets were coated by using different $\mathrm{pH}$ dependent polymers. Ethylcellulose, Eudragit RLPO and L100 were used as enteric coating polymers. The precompression blend of all formulations was subjected to various flow property tests and all the formulations were passed the tests. The tablets were coated by using polymers and the coated tablets were subjected to physical characterization, drug content, in vitro drug release and kinetics of drug release.

Results: Among all the formulations, F4 formulation was found to be optimized as it was retarded the drug release up to $18 \mathrm{~h}$ and showed maximum of $99.25 \%$ drug release. It followed the first-order kinetics mechanism. All the formulations having Korsmeyer-Peppas ' $n$ ' values are in the range of 0.540 to 0.818 . Hence, it was concluded that the prepared formulations followed non-Fickian diffusion.

Conclusion: An effective and stable remelteon colon targeted formulation developed for treating insomnia.

Keywords: Ramelteon, Colon targeted drug delivery system, Ethylcellulose, Eudragit RLPO, Eudragit L 100

(C) 2021 The Authors. Published by Innovare Academic Sciences Pvt Ltd. This is an open access article under the CC BY license (https://creativecommons.org/licenses/by/4.0/) DOI: https://dx.doi.org/10.22159/ijap.2021v13i2.40396. Journal homepage: https://innovareacademics.in/journals/index.php/ijap

\section{INTRODUCTION}

Now a days a novel oral colon-specific drug delivery system (CDDS) has been developed as one of the site-specific drug delivery systems. This delivery system, by means of the combination of one or more controlled release mechanisms, hardly releases drug in the upper part of the gastrointestinal (GI) tract, but rapidly releases drug in the colon following oral administration. First, as for treating localized colonic diseases, i.e. ulcerative colitis, Crohn's disease and constipation etc., the optimal drug delivery system, such as CDDS, should selectively deliver drug to the colon, but not to the upper GI tract $[1,2]$. Second, the colon is referred to as the optimal absorption site for protein and polypeptide after oral administration, because of the existence of relatively low proteolytic enzyme activities and quite long transit time in the colon. Finally, CDDS would be advantageous when a delay in absorption is desirable from a therapeutically point of view, as for the treatment of diseases that have peak symptoms in the early morning and that exhibit circadian rhythms, such as nocturnal asthma, angina and rheumatoid arthritis. There were currently a few strategies to achieve colonic specificity, such as use of $\mathrm{pH}$ sensitive polymers and pressure-controlled CDDS. The aim of this study was to explore the feasibility of the colonic microorganism to develop CDDS by using paracetamol as a model drug. Polysaccharides, the polymer of monosaccharides retains their integrity because they are resistant to the digestive action of gastrointestinal enzymes [3]. The matrices of polysaccharides are assumed to remain intact in the physiological environment of the stomach and small intestine, but once they reach in the colon, they are acted upon by the bacterial polysaccharides and results in the degradation of the matrices. A large number of polysaccharides such as amylose, guar gum, pectin, chitosan, inulin, cyclodextrins, chondroitin sulphate, dextrans, dextrin and locust bean gum have been investigated for their use in colon targeted drug delivery systems $[4,5]$. The most important fact in the development of polysaccharide derivatives for colon targeted drug delivery is the selection of a suitable biodegradable polysaccharide. As these polysaccharides are usually soluble in water, they must be made water-insoluble by cross linking or hydrophobic derivatization, very important is an optimal proportional of the hydrophobic and hydrophilic parts, respectively and the number of free hydroxyl groups in the polymeric molecule. The present study includes the preparation of ramelteon colon targeted tablets by using compression coating technology.

\section{MATERIALS AND METHODS}

\section{Materials}

Ramelteon was obtained as gift sample from Dr. Reddys Laboratories, Hyderabad, Andhrapradesh.

\section{Formulation of remelteon tablets}

Ramelteon colon targeted tablets were prepared by using compression coating technology. Initially, internal core tablet containing drug and super disintegrate was formulated. For the prepared core tablet compression coating is done by using various compositions of polymers. Ethyl cellulose, Polymethacrylate polymers such as Eudragit RLPO and Eudragit S100 are used as polymers for compression coating [6, 7].

\section{Formulation of core tablet}

The core tablets are formulated by using $8 \mathrm{mg}$ of the drug molecule, Cross carmellose sodium as super disintegrate, Micro crystalline cellulose as diluent, talc and magnesium stearate as Glidant and Lubricant, respectively. The composition of core tablet was given in below table 1 .

Table 1: Composition of core tablet

\begin{tabular}{ll}
\hline Ingredient name & Quantity (mg) \\
\hline Ramelteon & 8 \\
Cross carmellose sodium & 32 \\
Talc & 3 \\
Magnesium stearate & 3 \\
MCC pH102 & 34 \\
Total weight & 80 \\
\hline
\end{tabular}

Total weight of the core tablet was fixed as $80 \mathrm{mg}$. The tablets are prepared by using $6 \mathrm{~mm}$ flat punch. Then the prepared core tablets are subjected to compression coating by using various compositions of polymers. 


\section{Formulation of compression coated tablets}

The prepared core tablets were subjected to compression coating by using various compositions of polymers such as Ethylcellulose, Eudragit L 100 and Eudragit S 100 as coating materials [8, 9]. The composition of coating layer is given in below table 2 .

Table 2: Composition of the coating layer

\begin{tabular}{|c|c|c|c|c|c|c|c|c|c|}
\hline Ingredient name & F1 & F2 & F3 & F4 & F5 & F6 & F7 & F8 & F9 \\
\hline Ethyl cellulose (mg) & 40 & 80 & $-\cdots$ & --- & --- & ---- & 40 & ---- & 40 \\
\hline Eudragit RLPO (mg) & ---- & ---- & 40 & 80 & ---- & ---- & 40 & 40 & ---- \\
\hline Eudragit L 100 (mg) & ---- & ---- & ---- & ---- & 40 & 80 & ---- & 40 & 40 \\
\hline Magnesium stearate (mg) & 3 & 3 & 3 & 3 & 3 & 3 & 3 & 3 & 3 \\
\hline Talc (mg) & 3 & 3 & 3 & 3 & 3 & 3 & 3 & 3 & 3 \\
\hline MCC pH 102 (mg) & 174 & 134 & 174 & 134 & 174 & 134 & 174 & 134 & 174 \\
\hline Total weight & 220 & 220 & 220 & 220 & 220 & 220 & 220 & 220 & 220 \\
\hline
\end{tabular}

Compression coating layer was divided into two equal portions i.e., $110 \mathrm{mg}$ of each quantity. Half of the quantity of powder blend was placed in the die cavity, core tablet was placed exactly in the middle of die cavity and then remaining quantity of powder blend was placed over the core tablet so that the powder blend should cover all the sides and top side of core tablet uniformly. Then the tablets are compressed by using $9 \mathrm{~mm}$ flat-surfaced punch using 8 station tablet punching machine with the hardness of $4-4.5 \mathrm{~kg} / \mathrm{cm}^{2}$. Then the prepared compression coated tablets are evaluated for various postcompression parameters as per standard specifications.

\section{Physical characterization of fabricated tablets}

\section{Hardness}

The hardness of the tablet was determined by using a Monsanto hardness tester and expressed in $\mathrm{kg} / \mathrm{cm}^{2}[10,11]$.

\section{Uniformity of thickness}

The thickness of the three tablets was measured using Vernier calipers. The extent to which the thickness of each tablet deviates from $\pm 5 \%$ of the standard value was determined.

\section{Friability}

Percentage friability is calculated by given formulae that tells how much resistant to abrasion during manufacturing and packaging.

$$
\% \text { Friability }=\frac{(\mathrm{W} 1-\mathrm{W} 2)}{\mathrm{W} 1} \mathrm{x} 100
$$

$\mathrm{W}_{1}=$ Weight of tablets before test, $\mathrm{W}_{2}=$ Weight of tablets after the test.

\section{Weight variation}

Individual weights of 20 tablets were taken and the average weight was calculated by using the following formula and variation should not be more than $5 \%$.

$$
\text { Weight variation }=\frac{\text { Weight of tablet }- \text { Average weight }}{\text { Average weight of tablets }} \times 100
$$

\section{Determination of drug content}

Both compression-coated tablets of were tested for their drug content. Ten tablets were finely powdered quantities of the powder equivalent to one tablet weight of Ramelteon were accurately weighed, transferred to a $100 \mathrm{ml}$ volumetric flask containing $50 \mathrm{ml}$ water and were allowed to stand to ensure complete solubility of the drug. The mixture was made up to volume with water. The solution was suitably diluted and the absorption was determined by UVVisible spectrophotometer. The drug concentration was calculated from the calibration curve.

\section{In vitro drug release studies}

\section{Drug release studies of ramelteon core tablets}

The core tablets containing $8 \mathrm{mg}$ Ramelteon of were tested in $(\mathrm{pH}$ 6.8), for their dissolution rates. Dissolution studies were performed using USP paddle-type sample of $5 \mathrm{ml}$ was withdrawn and replaced with equal volume of fresh medium. The samples were analyzed spectrophotometrically at respective $256 \mathrm{~nm}[12,13]$.

\section{Drug release studies of compression coated ramelteon tablets}

The release of ramelteon from coated tablets was carried out using USP paddle-type dissolution apparatus at a rotation speed of 50 rpm, and a temperature of $37 \pm 0.5{ }^{\circ} \mathrm{C}$. For tablets, simulation of gastrointestinal transit conditions was achieved by using different dissolution media. Thus, drug release studies were conducted in simulated gastric fluid (SGF, $\mathrm{pH} 1.2$ ) for the first $2 \mathrm{~h}$ as the average gastric emptying time is about $2 \mathrm{~h}$. Then, the dissolution medium was replaced with enzyme-free simulated intestinal fluid (SIF, $\mathrm{pH}$ 7.4) and tested for drug release for $3 \mathrm{~h}$, as the average small intestinal transit time is about $3 \mathrm{~h}$, and finally, enzyme-free simulated intestinal fluid (SIF, $\mathrm{pH}$ 6.8) was used up to $18 \mathrm{~h}$ to mimic colonic $\mathrm{pH}$ conditions.

Drug release was measured from compression coated Ramelteon tablets, added to $900 \mathrm{ml}$ of dissolution medium. $5 \mathrm{ml}$ of sample was withdrawn every time and replaced with the fresh medium; samples were withdrawn at various time intervals were analyzed spectrophotometrically at $254 \mathrm{~nm}, 256 \mathrm{~nm}$ and $257 \mathrm{~nm}$, respectively. All dissolution runs were performed for six batches. The results were given with deviation $[14,15]$.

\section{Kinetics of in vitro drug release}

In vitro release data is applied to all the formulations (F1-F12) as per the given table 3 by using the equation and find the release mechanism.

Table 3: Kinetics of drug release

\begin{tabular}{lll}
\hline Type & Equation & Parameter \\
\hline Zero order & $Q_{t}=Q_{0}+K_{0} t$ & Cumulative percentage drug release vs. Time in hours \\
First order & $Q_{t}=Q_{0} \mathrm{e}^{-\mathrm{Kt}}$ & Log cumulative percentage remained vs. Time in hours \\
Higuchi & $\mathrm{Q}=\mathrm{K}_{\mathrm{h}} \mathrm{t}^{1 / 2}$ & Cumulative percentage drug release vs. Square root of time \\
Korsmeyer peppas & $\mathrm{F}=\left(\mathrm{Q}_{\mathrm{t}} / \mathrm{Q}\right)=\mathrm{K}_{\mathrm{m}} \mathrm{t}^{\mathrm{n}}$ & Log cumulative percentage of drug release vs. Log time \\
\hline
\end{tabular}

$\mathrm{Q} t=$ Cumulative amount of drug release at time " $\mathrm{t}$ ". $\mathrm{Q} 0=$ Initial amount of drug release, $\mathrm{Q}=$ Total amount of drug release in dosage forms, $\mathrm{N}=\mathrm{Diffusion}$ of release exponent, $\mathrm{T}=$ Time in hours, $\mathrm{K}_{0}, \mathrm{~K}, \mathrm{~K}_{\mathrm{h}}, \mathrm{K}_{\mathrm{m}}$ are release rate constants of Zero, First, Higuchi, Korsmeyer peppas

\section{RESULTS AND DISCUSSION}

Determination of absorption maxima
A solution of containing the concentration $10 \mu \mathrm{g} / \mathrm{ml}$ was prepared in $0.1 \mathrm{~N} \mathrm{HCl}, 7.4 \mathrm{pH}$ and phosphate buffer $6.8 \mathrm{pH}$ respectively, UV spectrum was taken using a Double beam UV/VIS 
spectrophotometer. The solution was scanned in the range of 200400.

\section{Preparation calibration curve}

$10 \mathrm{mg}$ of drug was accurately weighed and dissolved in $10 \mathrm{ml}$ of $0.1 \mathrm{~N} \mathrm{HCl}, 7.4 \mathrm{PH}$, and $6.8 \mathrm{PH}$ in $10 \mathrm{ml}$ volumetric flask, to make $(1000 \mu \mathrm{g} / \mathrm{ml})$ standard stock solution (1). Then $1 \mathrm{ml}$ stock solution (1) was taken in another $10 \mathrm{ml}$ volumetric flask to make (100 $\mu \mathrm{g} / \mathrm{ml}$ ) standard stock solution (2), then again $1 \mathrm{ml}$ of stock solution (2) was taken in another $10 \mathrm{ml}$ volumetric flask and then final concentrations were prepared $2,4,6,8,10$, with $0.1 \mathrm{~N} \mathrm{HCl}, 0.5,1,1.5$ and $27.4 \mathrm{pH}$, and 1,2,3,4 and 5 with $6.8 \mathrm{pH}$. The absorbance of standard solution was determined using UV/VIS spectrophotometer at $254 \mathrm{~nm}, 256 \mathrm{~nm}$ and $257 \mathrm{~nm}$. Linearity of the standard curve was assessed from the square of correlation coefficient (r2), which was determined by least-squares linear regression analysis. The graph plotted concentration vs. Absorbance [16, 17].

\section{Fourier transforms infrared spectroscopy}

\section{Preformulation studies}

Preformulation studies can be defined as investigations of physical and chemical properties of a new drug substance; either of the pure substance or of its combinations with other excipients. It is a phase of the research and development process that is required to develop stable, safe and effective dosage forms. These are also used for the determination of suitable excipients for the formulation of dosage forms.

\section{Drug-excipient compatibility study}

Drug excipient compatibility studies carried out by FTIR spectroscopy. The FTIR of pure drug and physical mixture of drug and excipient were studied. From FTIR, there was no significant change in the peaks of pure drug and excipient mixture [18]. Therefore it can be inferred that there was no specific interaction observed between the drug and the excipient, as shown in fig. 2

\section{Physical characterization of coated tablets}

All the formulations were prepared according to the formula given in table 1 . The prepared tablets were evaluated for various physical properties as indicated in table 4 . The results of evaluation studies can be summarized as follows:

The thickness of the formulations was found to be in the range of $4.40 \pm 0.5 \mathrm{~mm}$ to $4.9 \pm 0.5 \mathrm{~mm}$. the crushing strength of tablets is found to be 4.1 to $4.5 \mathrm{~kg} / \mathrm{cm} 2$. The loss in total weight of the tablets that is friability is less than $1 \%$. Weight variation was found to be in the range of 1.18 to $1.65 \%$. this shows that all the parameters are within limits and having good compressibility. Drug content is found to be $98.45 \%$ to $99.89 \%$ for all the formulation and having within limits.

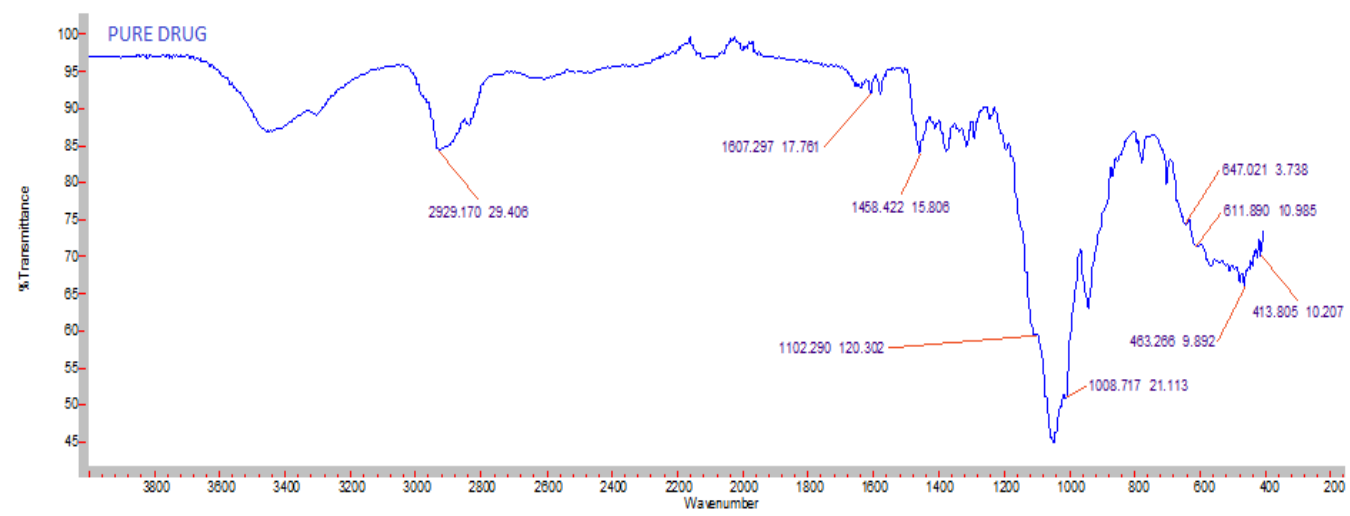

Fig. 1: FTIR spectrum of pure drug

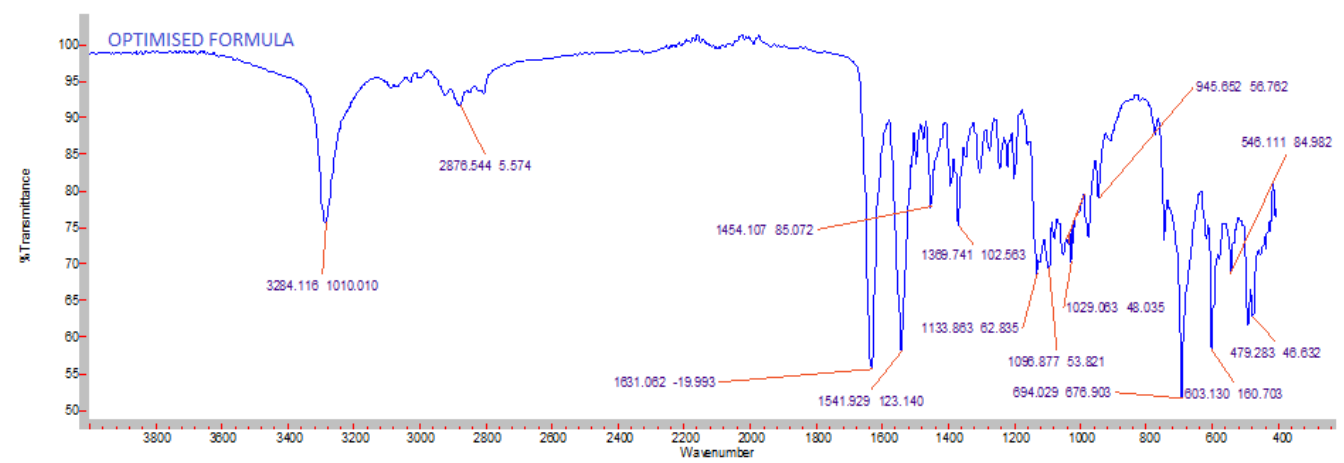

Fig. 2: FTIR spectrum of optimized formulation

Table 4: In vitro quality control parameters for compression coated tablets

\begin{tabular}{|c|c|c|c|c|c|}
\hline Formulation codes & Weight* variation (mg) & Hardness* (kg/cm2) & Friability* (\%loss) & Thickness (mm) & Drug content* (\%) \\
\hline F1 & $303.1 \pm 2.03$ & $4.5 \pm 0.26$ & $0.51 \pm 0.11$ & 4.8 & $99.77 \pm 0.58$ \\
\hline F2 & $304.2 \pm 3.04$ & $4.2 \pm 0.19$ & $0.53 \pm 0.19$ & 4.9 & $99.47 \pm 0.61$ \\
\hline F3 & $299.1 \pm 2.98$ & $4.4 \pm 023$ & $0.52 \pm 0.15$ & 4.9 & $99.35 \pm 0.78$ \\
\hline F4 & $309.3 \pm 3.47$ & $4.5 \pm 0.17$ & $0.56 \pm 0.17$ & 4.9 & $99.89 \pm 0.45$ \\
\hline F5 & $310.3 \pm 2.87$ & $4.4 \pm 0.24$ & $0.57 \pm 0.16$ & 4.7 & $99.15 \pm 0.54$ \\
\hline F6 & $311.5 \pm 1.99$ & $4.2 \pm 0.31$ & $0.46 \pm 0.11$ & 4.5 & $98.57 \pm 0.49$ \\
\hline F7 & $303.4 \pm 3.75$ & $4.1 \pm 0.17$ & $0.53 \pm 0.19$ & 4.4 & $98.45 \pm 0.48$ \\
\hline F8 & $304.6 \pm 4.12$ & $4.3 \pm 0.19$ & $0.48 \pm 0.18$ & 4.7 & $99.66 \pm 0.51$ \\
\hline
\end{tabular}




\begin{tabular}{lrrrrr}
\hline F9 & $299.4 \pm 3.75$ & $4.5 \pm 0.21$ & $0.56 \pm 0.19$ & 4.6 & $99.15 \pm 0.61$ \\
\hline
\end{tabular}

*mean $\pm \operatorname{SD}(\mathrm{n}=3)$

In vitro drug release of tablets

Table 5: In vitro drug release profile for coated formulations (F1-F9)

\begin{tabular}{|c|c|c|c|c|c|c|c|c|c|}
\hline Time (h) & F1* & F2* & F3* & F4* & F5* & F6* & F7* & F8* & F9* \\
\hline 0.5 & $4.76 \pm 0.65$ & $5.98 \pm 0.50$ & $6.89 \pm 0.15$ & $7.58 \pm 0.15$ & $3.89 \pm 0.36$ & $4.98 \pm 0.10$ & $6.85 \pm 0.44$ & $7.65 \pm 0.57$ & $4.25 \pm 0.55$ \\
\hline 1 & $10.55 \pm 0.51$ & $11.55 \pm 0.32$ & $15.66 \pm 0.31$ & $16.98 \pm 0.78$ & $12.55 \pm 0.26$ & $12.55 \pm 0.56$ & $14.82 \pm 0.38$ & $10.76 \pm 0.55$ & $8.95 \pm 0.67$ \\
\hline 2 & $10.47 \pm 0.21$ & $17.48 \pm 0.15$ & $22.69 \pm 0.15$ & $25.23 \pm 1.32$ & $19.77 \pm 0.32$ & $22.57 \pm 0.61$ & $21.03 \pm 0.61$ & $18.19 \pm 0.66$ & $14.3 \pm 0.50$ \\
\hline 3 & $30.68 \pm 0.32$ & $25.44 \pm 0.56$ & $35.63 \pm 0.50$ & $33.64 \pm 0.55$ & $26.76 \pm 0.21$ & $30.86 \pm 0.46$ & $28.6 \pm 0.84$ & $20.98 \pm 0.56$ & $19.88 \pm 0.60$ \\
\hline 4 & $43.75 \pm 0.61$ & $36.55 \pm 0.61$ & $48.87 \pm 0.59$ & $34.39 \pm 0.79$ & $32.85 \pm 0.66$ & $36.28 \pm 1.21$ & $33.35 \pm 0.72$ & $23.65 \pm 0.90$ & $24.89 \pm 0.82$ \\
\hline 5 & $49.79 \pm 0.82$ & $38.62 \pm 0.76$ & $52.45 \pm 0.56$ & $45.85 \pm 0.67$ & $38.75 \pm 0.76$ & $38.12 \pm 0.55$ & $45.26 \pm 0.38$ & $27.05 \pm 0.59$ & $28.18 \pm 0.55$ \\
\hline 6 & $50.06 \pm 0.93$ & $42.29 \pm 0.61$ & $54.98 \pm 0.31$ & $46.54 \pm 0.70$ & $43.38 \pm 0.45$ & $45.99 \pm 0.21$ & $46.27 \pm 0.85$ & $36.48 \pm 0.35$ & $35.67 \pm 0.59$ \\
\hline 7 & $55.65 \pm 0.15$ & $46.72 \pm 0.55$ & $57.72 \pm 1.11$ & $56.77 \pm 0.61$ & $45.23 \pm 0.70$ & $48.37 \pm 0.71$ & $54.25 \pm 0.72$ & $42.68 \pm 0.70$ & $45.35 \pm 0.75$ \\
\hline 8 & $58.39 \pm 0.40$ & $53.57 \pm 1.05$ & $59.93 \pm 0.61$ & $59.48 \pm 0.40$ & $50.55 \pm 0.66$ & $55.85 \pm 0.55$ & $60.93 \pm 0.46$ & $49.19 \pm 0.44$ & $48.93 \pm 0.90$ \\
\hline 9 & $67.98 \pm 0.67$ & $58.85 \pm 0.68$ & $65.53 \pm 1.80$ & $62.75 \pm 0.55$ & $57.28 \pm 0.75$ & $57.93 \pm 0.90$ & $65.33 \pm 0.93$ & $55.82 \pm 0.21$ & $52.08 \pm 0.90$ \\
\hline 10 & $68.79 \pm 0.81$ & $65.45 \pm 0.67$ & $67.56 \pm 0.72$ & $65.18 \pm 0.86$ & $63.49 \pm 0.95$ & $59.35 \pm 0.81$ & $66.09 \pm 0.71$ & $59.89 \pm 0.80$ & $58.15 \pm 0.78$ \\
\hline 11 & $70.35 \pm 0.52$ & $70.89 \pm 1.00$ & $72.83 \pm 0.44$ & $70.57 \pm 0.72$ & $67.76 \pm 0.68$ & $69.78 \pm 0.84$ & $69.37 \pm 0.70$ & $65.55 \pm 0.40$ & $63.65 \pm 0.82$ \\
\hline 12 & $73.36 \pm 0.85$ & $72.35 \pm 0.78$ & $75.48 \pm 0.78$ & $74.38 \pm 0.26$ & $79.66 \pm 0.65$ & $73.75 \pm 0.75$ & $70.45 \pm 0.66$ & $69.45 \pm 0.60$ & $65.09 \pm 0.57$ \\
\hline 13 & $77.57 \pm 0.78$ & $76.36 \pm 0.61$ & $77.15 \pm 0.55$ & $79.97 \pm 0.55$ & $83.76 \pm 0.59$ & $76.45 \pm 0.57$ & $73.26 \pm 0.93$ & $72.85 \pm 0.92$ & $69.71 \pm 0.75$ \\
\hline 14 & $81.64 \pm 0.44$ & $82.69 \pm 0.70$ & $82.36 \pm 0.87$ & $85.28 \pm 0.68$ & $85.18 \pm 0.26$ & $78.57 \pm 0.38$ & $77.25 \pm 0.62$ & $78.98 \pm 0.57$ & $73.38 \pm 0.95$ \\
\hline 15 & $84.55 \pm 0.47$ & $85.93 \pm 0.61$ & $84.78 \pm 0.78$ & $90.96 \pm 0.31$ & $88.67 \pm 0.56$ & $82.18 \pm 1.81$ & $80.8 \pm 0.55$ & $84.53 \pm 0.66$ & $76.45 \pm 0.75$ \\
\hline 16 & $86.69 \pm 0.32$ & $86.32 \pm 0.78$ & $87.99 \pm 0.55$ & $93.55 \pm 0.32$ & $90.32 \pm 1.05$ & $85.36 \pm 1.39$ & $85.36 \pm 0.87$ & $85.75 \pm 0.66$ & $80.27 \pm 0.60$ \\
\hline 17 & $88.89 \pm 0.61$ & $89.87 \pm 0.70$ & $89.43 \pm 1.25$ & $95.18 \pm 1.25$ & $91.86 \pm 0.40$ & $87.13 \pm 0.68$ & $87.85 \pm 0.32$ & $88.74 \pm 0.55$ & $82.89 \pm 0.81$ \\
\hline 18 & $90.16 \pm 0.92$ & $90.98 \pm 1.06$ & $93.19 \pm 0.56$ & $99.25 \pm 0.66$ & $90.98 \pm 0.66$ & $90.18 \pm 0.76$ & $89.26 \pm 0.74$ & $89.05 \pm 0.46$ & $85.99 \pm 0.95$ \\
\hline
\end{tabular}

$*_{\text {mean }} \pm \mathrm{SD}(\mathrm{n}=3)$

Table 6: Release kinetics data of ramelteon

\begin{tabular}{lllll}
\hline Formulation & Zero Order (R2) & First Order (R2) & Higuchi (R2) & \multicolumn{1}{c}{ Korsmeyer-Peppas } \\
\cline { 3 - 4 } & & & & (R2) \\
\hline F1 & 0.917 & 0.988 & 0.975 & 16.117 \\
F2 & 0.975 & 0.974 & 0.981 & 12.48 \\
F3 & 0.925 & 0.971 & 0.988 & 19.72 \\
F4 & 0.978 & 0.851 & 0.986 & 15.37 \\
F5 & 0.973 & 0.956 & 0.97 & 11.744 \\
F6 & 0.969 & 0.978 & 0.987 & 14.11 \\
F7 & 0.950 & 0.982 & 0.989 & 0.645 \\
F8 & 0.987 & 0.96 & 0.735 \\
F9 & 0.984 & 0.981 & 0.956 & 0.649 \\
\hline
\end{tabular}

\section{Kinetics of drug release}

\section{Kinetics of in vitro drug release}

In vitro release data obtained is applied to all the formulations (F1F9) as per the table 2. The kinetic profiles of all formulations were shown in table 6 . The correlation coefficient $(r)$ values in the analysis of release data as per various models are given table 6 . Analysis of the release data as per zero order and first-order kinetic models indicated that the drug release from matrix tablets followed first-order kinetics. All the formulations followed first order kinetics. This implies that the drug release is dependent on one of the concentrations. The correlation coefficient $(r)$ values were higher in first order model when compared to zero-order models. The $r$ values were also higher in the Higuchi and Peppas equation models indicating that the drug release from the ramelteon tablets also obeyed these two models. When the release date are analyzed as per Peppas equation, the release exponent ' $n$ ' is an empirical parameter characterizing the release mechanism $[19,20]$. Mechanism of drug release may be determined based on the values of the diffusion exponent, if the value of $\mathrm{n}$ is 0.5 it indicates that the drug release mechanism is explained by a Fickian diffusion-controlled release, whereas if $n$ equal to 1.0 , it indicates that the drug release mechanism approaches to zero order release. If $n$ value is from 0.5 to 1 , it implies that the release mechanism is non-Fickian diffusion or chain relaxation control release. The $n$ value of the formulations was in the range of 0.540 to 0.818 .

Hence, it was concluded that the prepared formulations followed non-Fickian diffusion. The drug release from all the batches followed by non-ficikian diffusion mechanism as Higuchi's fit shows high correlation coefficient values [21]. Among all the formulations F4 formulation was found to be optimized as it was retarded the drug release up to $18 \mathrm{~h}$ and showed maximum of $99.25 \%$ drug release.

\section{CONCLUSION}

In the present research work formulation of ramelteon targeted to colon was prepared by using various polymers. Colon-targeted tablets were prepared in two steps. Initially, core tablets were prepared and then the tablets were coated by using different $\mathrm{pH}$ dependent polymers. Ethylcellulose, Eudragit L100 and Eudragit RLPO were used as enteric coating polymers. The pre-compression blend of all formulations was subjected to various flow property tests and all the formulations were passed the tests. The tablets were coated by using polymers and the coated tablets were subjected to various evaluation techniques. The tablets were passed all the tests. Among all the formulations, F4 formulation was found to be optimized as it was retarded the drug release up to $18 \mathrm{~h}$ and showed maximum of $99.25 \%$ drug release. It followed the first order kinetics mechanism.

\section{CONFLICT OF INTERESTS}

The authors declare that they do not have any financial and personal relationships with other people or organisation that could in appropriately influence their work.

\section{ACKNOWLEDGEMENT}

We express our sincere thanks to Dr L. Rathaiah, Chairman Vignan Group of Institutions for providing the necessary facilities to carry out the above project work. 


\section{FUNDING}

\section{Nil}

\section{AUTHORS CONTRIBUTIONS}

All the authors have contributed equally.

\section{CONFLICT OF INTERESTS}

Declared none

\section{REFERENCES}

1. Gadhave MV, Shevante Trupti B, Takale Avinash A, Jadhav SL, Gaikwad D. Formulation and evaluation of colon targeted drug delivery of mesalamine. Int J Pharm Clin Res 2017;9:26-34

2. Siamidi A, Vlachou M, Efentakis M. New dosage forms for the delayed release of mesalazine to the colon. Int J Appl Pharm 2020;12:192-6.

3. Washington N, Washington C, Wilson CG. Physiological pharmaceutics: barriers to drug absorption. Taylor Francis 2001;10:144-9.

4. Bharat W Tekade, Umesh T Jadhao, Vicky R Vig, Vijay R Patil. Formulation and evaluation of colon-specific drug delivery system using Boswellia serrata gum. Pharma Innovation 2017;6:277-83.

5. Rajesh K, Deveswaran R, Bharath S, Basavaraj BV. Development of mesalazine microspheres for colon targeting. Int J Appl Pharm 2017;9:1-9.

6. Jagan Baheka, Shailesh Wadher. Formulation development of colon targeted mesalamine pellets: in vitro-in vivo release study. Int J Appl Pharm 2019;11:132-5.

7. Sajaymitra GN, K Ganesh. Dissolution and solubility enhancement strategies: current and novel prospectives. JCR 2018;5:1-10.

8. Sirisha VN, Eswariah MC, Rao AS. A novel approach of locust bean gum microspheres for colonic delivery of mesalamine. Int J Appl Pharm 2018;10:86-93.

9. Goyal N, A Kumar. Formulation and in vitro evaluation of salbutamol sulphate and theophylline extended-release tablets using modified polymers. Int J Pharm Sci 2018;10:67-71.
10. Rawoof MD, Rajnarayana K, Ajitha M. Formulation and evaluation of ph-dependent colon-targeted tablets of rifaximin by design of an experiment. Asian J Pharm Clin Res 2019;12:249-54.

11. Purushothaman M. Kalvimoorthi formulation and evaluation of colon targeted drug delivery system of flurbiprofen using HPMC and K4M sodium alginate as polymeric carrier. Int J ChemTech Res 2017;10:156-68.

12. Biresh Kumar Sarkar, Jain DA, Vikram Sharma. Formulation and evaluation of flurbiprofen matrix tablets for colon targeting. Int J Pharma Chem Sci 2012;1:95-9.

13. Wu, Z Chen, $\mathrm{X}$ Wei, $\mathrm{N}$ Sun, $\mathrm{Y}$ Lu, W Wu. Biphasic release of indomethacin from HPMC/pectin/calcium matrix tablet: I. Characterization and mechanistic study. Eur J Pharm Biopharm 2007:67:707-14.

14. Ravi, S Siddaramaiah, TM Pramod Kumar. Influence of natural polymer coating on novel colon targeting drug delivery system. J Mater Sci Mater Med 2008;19:2131-6.

15. Talukder, R Fassihi. Development and in vitro evaluation of a colon-specific controlled release drug delivery system. J Pharm Pharmacol 2008;60:1297-303.

16. Udayasree Konikuru, Rajavel P, Vijitha S. Bioequivalence studies of marketed clozapine tablets by using optimized validated liquid chromatographic method. Int J Curr Pharm Res 2018;10:47-51.

17. Rao MT, Vijaya Ratna J, Srinivasa Rao Y, Hemant Kumar T. Development and validation of RP-HPLC method for the determination of itraconazole in bulk and capsule dosage form. Int J Pharm Sci Rev Res 2015;31:221-5.

18. Vemula $\mathrm{P}, \mathrm{R}$ Veerareddy. Formulation, evaluation and pharmacokinetics of ketorolac tromethamine time-dependent colon targeted drug delivery system. Expert Opin Drug Delivery 2013;10:33-45

19. Pena R, Verain. Analysis of different parameters of an optimized prolonged-release formulation obtained by five processes. Pharma Technol Con Drug Release Ellis Horwood London 2005;2:57-70.

20. Costa P, Manuel J, Lobo S. Modeling and comparison of dissolution profiles. Eur J Pharm Sci 2001;13:123-33.

21. Korsmeyer RW, Peppas NA, Gurney R, Deckar B, Buri PP. Mechnism of solute release from porous hydrophilic polymers. Int J Pharm 1983;15:35-9. 